\title{
The Effect of Cancer Chemotherapeutic Agents on Fibrin Formation and Stabilization in Vitro
}

\author{
Diane M. Komp, ${ }^{132]}$ Robert L. Lyles, Jr., Thomas H. Boyd, III, \\ Glenn E. Stoner, and Betty J. Cox \\ Departments of Pediatrics and Materials Science, University of Virginia, Charlottesville, Virginia, USA
}

\begin{abstract}
Extract
Functional and morphologic studies of fibrin formation in the presence of a variety of cancer chemotherapeutic agents in vitro showed that some of these drugs cause fibrinolysis, inactivation of fibrin-stabilizing factor (FSF), or a combination of both. The drugs with most potent activity are 5-[3,3-bis(2-chloroethyl)-1-triazeno]imidazole-4carboxamide (TIC mustard), 5-fluorouracil, nitrogen mustard, adriamycin, and daunomycin. These changes were dose related.
\end{abstract}

\section{Speculation}

Interference with fibrin formation by anticoagulation has been associated with reduced implantability of tumor emboli in experimental systems. This study presents evidence that some cancer chemotherapeutic agents have chemical properties of an anticoagulant nature. In addition to any influence on cell multiplication, high pulse doses of adjuvant chemotherapy at the time of tumor manipulation such as surgery may interfere with fibrin formation around tumor emboli and discourage metastatic implantation.

\section{Introduction}

In a variety of animal tumor systems [5-7, 9, 16], successful implantation of metastases is related to fibrin formation and platelet aggregation around the embolized tumor cells. Inhibitors of fibrin formation (heparin [7] and coumadin [14]), inhibitors of platelet aggregation (aspirin [11\}), inhibitors of fibrin stabilization (poly-L-lysine [12]), accelerators of fibrinolysis (plasmin [3]), and inducers of thrombocytopenia (neuraminidase [8]) have been reported to decrease the numbers of metastases in these tumor systems. Conversely, $\epsilon$-aminocaproic acid ( $\epsilon$-ACA) and Trasylol, potent inhibitors of fibrinolysis, allow for more rapid fixation of tumor emboli [5]. In all of these systems, the inhibitor had to be present at the time tumor emboli were attempting to implant to exert its effect.

Remarkably similar inhibition of tumor metastases have been reported with the administration of nitrogen mustard [6] and triethylenethiophosphoramide [10]. It has generally been assumed that the role of adjuvant chemotherapy at the time of tumor manipulation is to reduce metastases by interfering with cell multiplication. Cliffton and Agostino [4] suggested that the protective effect might involve action of the coagulation system. It is the purpose of this paper to report in vitro studies of the influence of a variety of cancer chemotherapeutic agents on fibrin formation and stabilization.

\section{Materials and Methods}

\section{Normal Plasma}

The same six normal donors were used throughout the studies. Blood was anticoagulated using a ratio of 
9 parts whole blood to 1 part $3.8 \%$ sodium citrate. After centrifugation at $4^{\circ}$ for $15 \mathrm{~min}$ at $1,500 \mathrm{rpm}$, platelet-poor plasma was separated, pooled, and frozen in small aliquots in siliconized tubes. Aliquots were thawed just before use.

\section{Chemotherapeutic Agents}

The following drugs were dissolved with their appropriate solvent for intravenous administration: vincristine (Oncovin) [17], vinblastine (Velban) [17], cytosine arabinoside (Cytosar) [18], actinomycin D (Cosmogen) [19], methotrexate [20], cyclophosphamide (Cytoxan) [21], nitrogen mustard (Mustargen) [18], daunorubricin [22], adriamycin [22], L-asparaginase [19], 5-fluorouracil [23], and TIC mustard [24]. Further dilutions were made with sterile solvent just before use in testing. Table I lists the agent, its solvent, and the concentration of a $1 / 1$ dilution. Test dilutions were chosen to approximate high concentrations anticipated with perfusion rather than plasma levels after infusion.

\section{Serial Thrombin Time}

Bovine thrombin [25] was dissolved with normal $\mathrm{NaCl}$ solution to give a concentration of $10 \mathrm{U} / \mathrm{mI}$ and was stored frozen in siliconized tubes until just before use. Thrombin solution was kept in a melting ice bath during use in testing.

Plasma $(0.1 \mathrm{ml})$ and drug dilution $(0.1 \mathrm{ml})$ were placed in Fibrometer [26] cups on a heating block. Thrombin time was determined at 0 - and 60-min incubation at $37^{\circ}$ by the addition of $0.1 \mathrm{ml}$ thrombin solution. All determinations were performed in duplicate. Control tests were performed substituting the appropriate solvent for the drug. Drugs associated

Table I. Chemotherapeutic agent, solvent, and concentration

\begin{tabular}{lrll}
\hline \multicolumn{1}{c}{ Drug } & NSC no. & Solvent & $\begin{array}{c}\text { 1/1 Dilution, } \\
\mathbf{M}\end{array}$ \\
\hline Vincristine & 67574 & Normal saline & $1.2 \times 10^{-4}$ \\
Vinblastine & 49842 & Normal saline & $1.2 \times 10^{-3}$ \\
Actinomycin D & 3053 & Sterile water & $3.1 \times 10^{-4}$ \\
Cytosine arabinoside & 63878 & Sterile water & $6.7 \times 10^{-2}$ \\
Methotrexate & 740 & Sterile water & $1.1 \times 10^{-2}$ \\
Cyclophosphamide & 26271 & Sterile water & $1.8 \times 10^{-1}$ \\
Nitrogen mustard & 762 & Sterile water & $8.4 \times 10^{-3}$ \\
Daunorubricin & 82151 & Sterile water & $3.9 \times 10^{-3}$ \\
Adriamycin & 123127 & Sterile water & $1.8 \times 10^{-3}$ \\
L-Asparaginase & 109229 & Sterile water & $2,000^{2}$ \\
5-Flurouracil & 19896 & Normal saline & $7.8 \times 10^{-3}$ \\
TIC mustard & 82196 & 0.01 N HCl & $7.7 \times 10^{-2}$ \\
\hline
\end{tabular}

I With benzyl alcohol preservative.

2 Units per milliliter.

35-[3,3-Bis(2-chloroethyl)-1-triazeno]imidazole-4-carboxamide. with progressive lengthening of thrombin time on incubation were restudied adding $\epsilon$-ACA (Amicar) [20] to the drug solvent to give a concentration of $0.1 \mathrm{M} \epsilon^{-}$ ACA.

\section{Urea Solubility}

Equal volumes of normal plasma and $1 / 1$ drug dilution (see Table I) were incubated at $37^{\circ}$ for $60 \mathrm{~min}$ in glass tubes in a water bath. Clots were formed by recalcification of $1 \mathrm{ml}$ mixture with $0.1 \mathrm{ml} 0.25 \mathrm{M}$ $\mathrm{CaCl}_{2}$. The clots were suspended in a solution of $5 \mathrm{M}$ urea and observed during the next $48 \mathrm{hr}$ for dissolution. Saline and the appropriate drug solvents were substituted for drug in control determinations. Abnormal studies were repeated with the addition of $\epsilon$-ACA to the drug solvent before mixing with plasma.

\section{pH Studies}

Equal parts of plasma were mixed with a $1 / 1$ drug dilution and allowed to come to room temperature before the $\mathrm{pH}$ was determined by a Digicord $\mathrm{pH}$ meter [27]. Samples that were very alkaline were acidified drop-wise with $0.1 \mathrm{~N} \mathrm{HCl}$. Acid samples were alkalinized with $0.1 \mathrm{~N} \mathrm{NaOH}$. In studies with 5-fluorouracil it was necessary to acidify with $1 \mathrm{~N} \mathrm{HCl}$ in order to accomplish decremental $\mathrm{pH}$ changes without excessive dilution. Thrombin time was performed as above on samples for each $\mathrm{pH}$ unit change of 0.1. Plasma-drug samples at $\mathrm{pH} 7.6$ were recalcified with $0.025 \mathrm{M} \mathrm{CaCl}_{2}$. Fibrin thus formed was placed in $5 \mathrm{M}$ urea and observed for solubility.

\section{Electrical Resistance Studies}

Two milliliters of plasma were activated by mixing in a clean glass tube (12 by $75 \mathrm{~mm}$ ) for $3 \mathrm{~min}$. Twotenths milliliter of a $1 / 2$ drug dilution and $0.2 \mathrm{ml} 0.25$ $\mathrm{M} \mathrm{CaCl}_{2}$ were added sequentially with thorough mixing after each addition. The plasma was then placed in an aluminum incubation cell at $37^{\circ}$. The polymerization of the resulting fibrin was monitored by measuring the Dc resistance of the plasma with an electrometer [28]. Optical density was monitored simultaneously. A pair of spherical microelectrodes melted and shaped from gold wire, $1.5 \mathrm{~cm}$ in length by 0.008 inch in diameter [29], were suspended in the tube of plasma with a pair of plain glass capillary tubes [30]. "Incubated" studies were performed by addition of drug to plasma $1 \mathrm{hr}$ at $39^{\circ}$ before glass activation and recalcifcation. 


\section{Electron Microscopy (Figs. 1 and 2)}

Normal plasma was mixed with a $1 / 2$ drug dilution in the ratio of 2 parts plasma to 1 part drug. All samples except for $\mathrm{HN}_{2}$ and TIC mustard were incubated at $37^{\circ}$ for $60 \mathrm{~min}$. After incubation, $2 \mathrm{ml}$ drugplasma sample were activated in glass for $3 \mathrm{~min}$ and then recalcified by the addition of $0.2 \mathrm{ml} 0.25 \mathrm{M} \mathrm{CaCl}_{2}$. The plasma was pipetted into a $19 \mathrm{~cm}$ length of silicon rubber tubing with an internal diameter of $3 \mathrm{~mm}$. The plasma was allowed to flow over the surface of a carbon plastic film mounted on an electron microscope grid on a substrate holder. Both ends of the tubing were inserted into the substrate holder to form a closed loop [3]. The circular tube was then secured on a turntable and rotated at $15 \mathrm{rpm}$ until a fibrin clot formed in the moving plasma column. The specimens were removed from the substrate holder and fixed in $10 \%$ formalin for 12 hours.

In preparation for electron microscopy, the samples were stained for 2 min with uranyl acetate, washed in

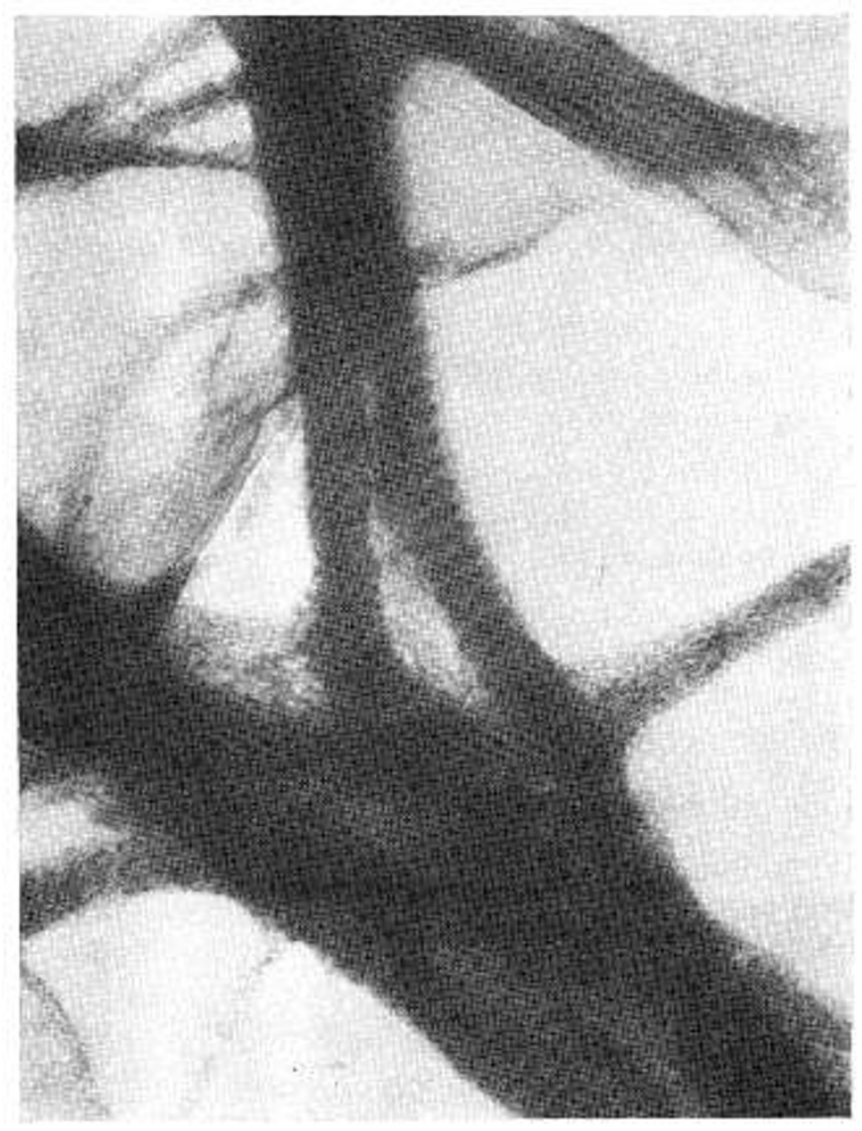

Fig. 1. Electron micrograph of fibrin formed from plasma containing vincristine $(\times 70,000), \mathrm{pH} 7.9$.

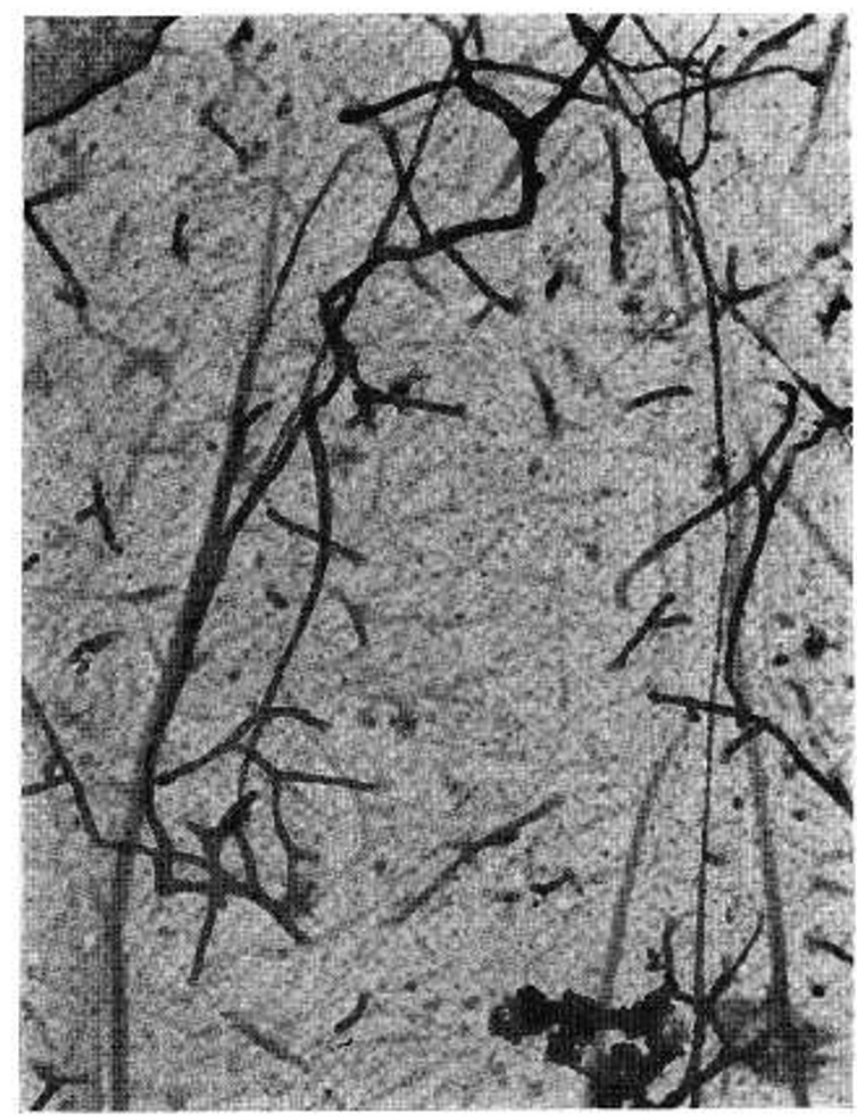

Fig. 2. Electron micrograph of fibrin formed from plasma containing 5-[3,3-bis(2-chloroethyl)-1-triazeno]imidazole-4-carboxamide $(\times 10,000) \mathrm{pH} 3.7$.

distilled water, and air-dried. The microscopy was performed on a JEM-6A transmission electron microscope at $100 \mathrm{kV}$.

\section{Results}

\section{Serial Thrombin Time}

On the basis of serial thrombin times of mixtures of chemotherapeutic agents with plasma, drugs could be divided into three classes: class $I$, no influence on thrombin time; class $I X$, abnormal incubated thrombin time corrected by premixture with $\epsilon$-ACA; class III, markedly abnormal thrombin time with and without incubation; no correction by premixture of incubated specimen with $\epsilon$-ACA.

Table II summarizes the thrombin times for each drug at three dilutions. Thrombin times that were abnormal were less so as the concentration of drug was decreased. Substitution of normal saline with benzyl alcohol, normal saline without preservative, distilled 
Table II. Influence of drugs on serial thrombin time ${ }^{1}$

\begin{tabular}{|c|c|c|c|}
\hline \multirow{2}{*}{ Dilution } & \multicolumn{3}{|c|}{ Thrombin time; $\mathrm{s}$} \\
\hline & $0 \min$ & $60 \mathrm{~min}$ & With $\epsilon-\mathrm{ACA}$ \\
\hline \multicolumn{4}{|l|}{ Class $I$} \\
\hline \multicolumn{4}{|l|}{ Vincristine } \\
\hline $1 / 1$ & 6.3 & 12.3 & \\
\hline $1 / 2$ & 6.8 & 11.3 & \\
\hline $1 / 4$ & 6.8 & 12.0 & \\
\hline \multicolumn{4}{|l|}{ Vinblastine } \\
\hline $1 / 1$ & 5.8 & 11.0 & \\
\hline $1 / 2$ & 6.3 & 11.8 & \\
\hline $1 / 4$ & 6.8 & 12.8 & \\
\hline \multicolumn{4}{|l|}{ Cytosine arabinoside } \\
\hline $1 / 1$ & 6.8 & 10.6 & \\
\hline $1 / 2$ & 6.4 & 12.6 & \\
\hline $1 / 4$ & 6.4 & 14.4 & \\
\hline \multicolumn{4}{|l|}{ L-Asparaginase } \\
\hline $1 / 4$ & 7.3 & 10.5 & \\
\hline $1 / 2$ & 6.3 & 10.8 & \\
\hline $1 / 4$ & 7.3 & 11.0 & \\
\hline \multicolumn{4}{|l|}{ Adriamycin } \\
\hline $1 / 1$ & 6.1 & 9.4 & \\
\hline $1 / 2$ & 6.4 & 10.9 & \\
\hline $1 / 4$ & $\because \quad 6.9$ & $11: 4$ & \\
\hline \multicolumn{4}{|l|}{ Daunorubricin } \\
\hline $1 / 1$ & $6: 9$ & $11: 1$ & \\
\hline $1 / 2 \cdots$ & $6: 9$ & 14.0 & \\
\hline $1 / 4$ & 6.9 & 15.9 & \\
\hline \multicolumn{4}{|l|}{ Class III } \\
\hline \multicolumn{4}{|l|}{ Actinomycin $\mathrm{D}$} \\
\hline $1 / 1$ & 7.3 & 23.3 & 11.1 \\
\hline $1 / 2$ & 6.8 & 19.0 & \\
\hline $1 / 4$ & 7.3 & 16.2 & \\
\hline \multicolumn{4}{|l|}{ Cyclophosphamide } \\
\hline $1 / 1$ & 10.1 & 63.3 & 20.4 \\
\hline $1 / 2$ & 7.4 & 18.9 & \\
\hline $1 / 4$ & 6.9 & 11.9 & \\
\hline \multicolumn{4}{|l|}{ Nitrogen mustard } \\
\hline $1 / 1$ & 7.4 & 105.9 & 21.4 \\
\hline $1 / 2$ & 6.4 & 42.3 & \\
\hline $1 / 4$ & 6.4 & 22.4 & \\
\hline \multicolumn{4}{|l|}{ Methotrexate } \\
\hline $1 / 1$ & 10.3 & 39.5 & 23.0 \\
\hline $1 / 2$ & 7.8 & 21.0 & \\
\hline $1 / 4$ & 7.5 & 15.8 & \\
\hline \multicolumn{4}{|l|}{ Class III } \\
\hline \multicolumn{4}{|l|}{ 5-Fluorouracil } \\
\hline $1 / 1$ & 180.4 & $>800$ & $>800$ \\
\hline $1 / 2$ & 68.8 & 115.3 & \\
\hline $1 / 4$ & 33.4 & 60.3 & \\
\hline \multicolumn{4}{|l|}{ TIC mustard } \\
\hline $1 / 1$ & $>500$ & $>500$ & $>500$ \\
\hline $1 / 2$ & $>500$ & $>500$ & \\
\hline $1 / 4$ & 8.9 & 7.9 & \\
\hline Normal range & $6.1-7.9$ & $8.7-17.5$ & \\
\hline
\end{tabular}

${ }^{1} \epsilon$-ACA: $\epsilon$-aminocaproic acid; TIC mustard: 5 -[3,3-bis (2chloroethyl)-1-triazeno]imidazole-4-carboxamide. water of $0.01 \mathrm{~N} \mathrm{HCl} \mathrm{did} \mathrm{not} \mathrm{prolong} \mathrm{control} \mathrm{thrombin}$ times (Table III).

Stepwise correction of $\mathrm{pH}$ towards 7.4 for classes II and III drugs reduced the magnitude of the thrombin time abnormality (Table IV). However, normal throm-

Table III. Influence of drug solvents on serial thrombin time and urea solubility

\begin{tabular}{|c|c|c|c|}
\hline \multirow{2}{*}{ Solvent } & \multicolumn{2}{|c|}{ Thrombin time, $\mathrm{s}$} & \multirow{2}{*}{$\begin{array}{l}\text { Urea solu- } \\
\text { bility, } \mathrm{hr}\end{array}$} \\
\hline & $0 \mathrm{~min}$ & $60 \mathrm{~min}$ & \\
\hline Sterile water $(8)^{1}$ & $6.3-7.8$ & $10.4-17.9$ & $>24$ \\
\hline $\begin{array}{l}\text { Normal saline with } \\
\text { benzyl alcohol (3) }\end{array}$ & $6.4-7.3$ & $12.0-12.8$ & $>24$ \\
\hline $0.01 \mathrm{~N} \mathrm{HCl}(1)$ & 6.4 & 7.4 & $<24$ \\
\hline Normal saline (12) & $6.1-7.9$ & $8.7-17.5$ & $>24$ \\
\hline
\end{tabular}

1 Number of duplicate determinations are indicated in parentheses.

Table $\mathrm{IV}$. Influence of $\mathrm{pH}$ on serial thrombin time

\begin{tabular}{|c|c|c|c|}
\hline \multirow{2}{*}{ Drug } & \multirow{2}{*}{ Class } & \multicolumn{2}{|c|}{ Thrombin time, s } \\
\hline & & $0 \mathrm{~min}$ & $60 \mathrm{~min}$ \\
\hline \multicolumn{4}{|l|}{$\mathrm{pH} 7.4$} \\
\hline Adriamycin & $I$ & 5.4 & 6.2 \\
\hline Daunorubricin & $I$ & 7.4 & 6.7 \\
\hline Cytosine arabinoside & $I$ & 7.4 & 11.2 \\
\hline Nitrogen mustard & II & 7.9 & 80.4 \\
\hline Methotrexate & $I I$ & 9.9 & 17.4 \\
\hline Cyclophosphamide & $I I$ & 8.4 & 16.7 \\
\hline 5-Fluorouracil & $I I I$ & 105.5 & 218.4 \\
\hline \multicolumn{4}{|l|}{ pH 7.5} \\
\hline Adriamycin & $I$ & 4.9 & 6.9 \\
\hline L-Asparaginase & $I$ & 6.0 & 9.2 \\
\hline Nitrogen mustard & $I I$ & 7.9 & 105.9 \\
\hline Cyclophosphamide & II & 8.4 & 18.9 \\
\hline \multicolumn{4}{|l|}{ pH 7.6} \\
\hline Daunomycin & $I$ & 5.4 & 7.7 \\
\hline Nitrogen mustard & $I I$ & 7.9 & 129.4 \\
\hline 5-Fluorouracil & $I I I$ & 134.9 & 230.5 \\
\hline \multicolumn{4}{|l|}{ pH 7.7} \\
\hline Nitrogen mustard & II & 8.1 & 131.4 \\
\hline Cyclophosphamide & II & 8.4 & 22.4 \\
\hline \multicolumn{4}{|l|}{ pH 7.8} \\
\hline Adriamycin & $I$ & 5.2 & 7.2 \\
\hline Cyclophosphamide & $I I$ & 9.4 & 29.4 \\
\hline 5-Fluorouracil & $I I I$ & 154.9 & $>400$ \\
\hline \multicolumn{4}{|l|}{ pH 7.9} \\
\hline Daunomycin & $I$ & 5.9 & 9.4 \\
\hline Methotrexate & $I I$ & 9.9 & 17.4 \\
\hline \multicolumn{4}{|l|}{ pH 8.0} \\
\hline Adriamycin & $I$ & 6.1 & 9.4 \\
\hline L-Asparaginase & $I$ & 6.0 & 11.7 \\
\hline 5-Fluorouracil & III & 155.9 & $>400$ \\
\hline Normal range & & $6.1-7.9$ & $8.7-17.5$ \\
\hline
\end{tabular}

1 Nitrogen. 
bin times were observed with class $I$ agents at similar extremes of $\mathrm{pH}$.

\section{Urea Solubility}

Plasma containing normal saline without preservative, distilled water without preservative, or normal saline with benzyl alcohol resisted solubility in $\mathbf{5} \mathbf{~ M ~}$ urea during the $48 \mathrm{hr}$ of observation. Plasma which contained $0.01 \mathrm{~N} \mathrm{HCl}$ produced recalcified clots that dissolved in less than $24 \mathrm{hr}$ in $5 \mathrm{M}$ urea (Table III).

Four classes of agents could be discerned by the pattern of urea solubility. These classes corresponded strictly to those constructed on the basis of thrombin times except for a subdivision among the agents without influence on serial thrombin time (class I). Subclass $A$, exemplified by vincristine, vinblastine, actinomycin $\mathrm{D}$, and cytosine arabinoside, showed normal resistance to solubility in $5 \mathrm{M}$ urea. Subclass $B$ agents, daunorubricin, adriamycin, and L-asparaginase, although without influence on the thrombin time, did influence urea solubility. This solubility was not influenced by prior incubation with $\epsilon$-ACA. Adjustment of the $\mathrm{pH}$ to 7.6 before recalcification did prevent dissolution of clots formed in plasma containing L-asparaginase. Clots formed in the presence of daunorubricin and adriamycin remained soluble in $5 \mathrm{M}$ urea despite adjustment of the $\mathrm{pH}$ to 7.6.

Class II agents such as methotrexate, cyclophosphamide, and $\mathrm{HN}_{2}$ were associated with progressive prolongation of thrombin time and increased urea solubility. Prior incubation with $\epsilon$-ACA prevented urea solubility. Adjustment of $\mathrm{pH}$ to 7.6 did not prevent urea solubility in the absence of $\epsilon$-ACA.

The protective effect of incubation with $\epsilon$-ACA on urea solubility was not seen with class III agents. Adjustment of $\mathrm{pH}$ to 7.6 for 5-fluorouracil did not prevent urea solubility.

\section{Electrical Resistance Studies}

During clot formation, a sigmoid curve with two inflections portrays the changes in electrical resistance in normal plasma. At the recalcification time, the electric resistance of the plasma increases markedly, seen by the first inflection (1) in the curve (Fig. 3). Normally, the electrical resistance again shows another sharp increase displaying a broader inflection ( 2 ). Abnormal curves were observed for all drugs in classes $I-B, I I$, and $I I I$. The values for the time after recalcification for the inscription of the second inflection are summarized in Table V. Delay of the second inflection corresponded to solubility of fibrin in urea (Table VI).

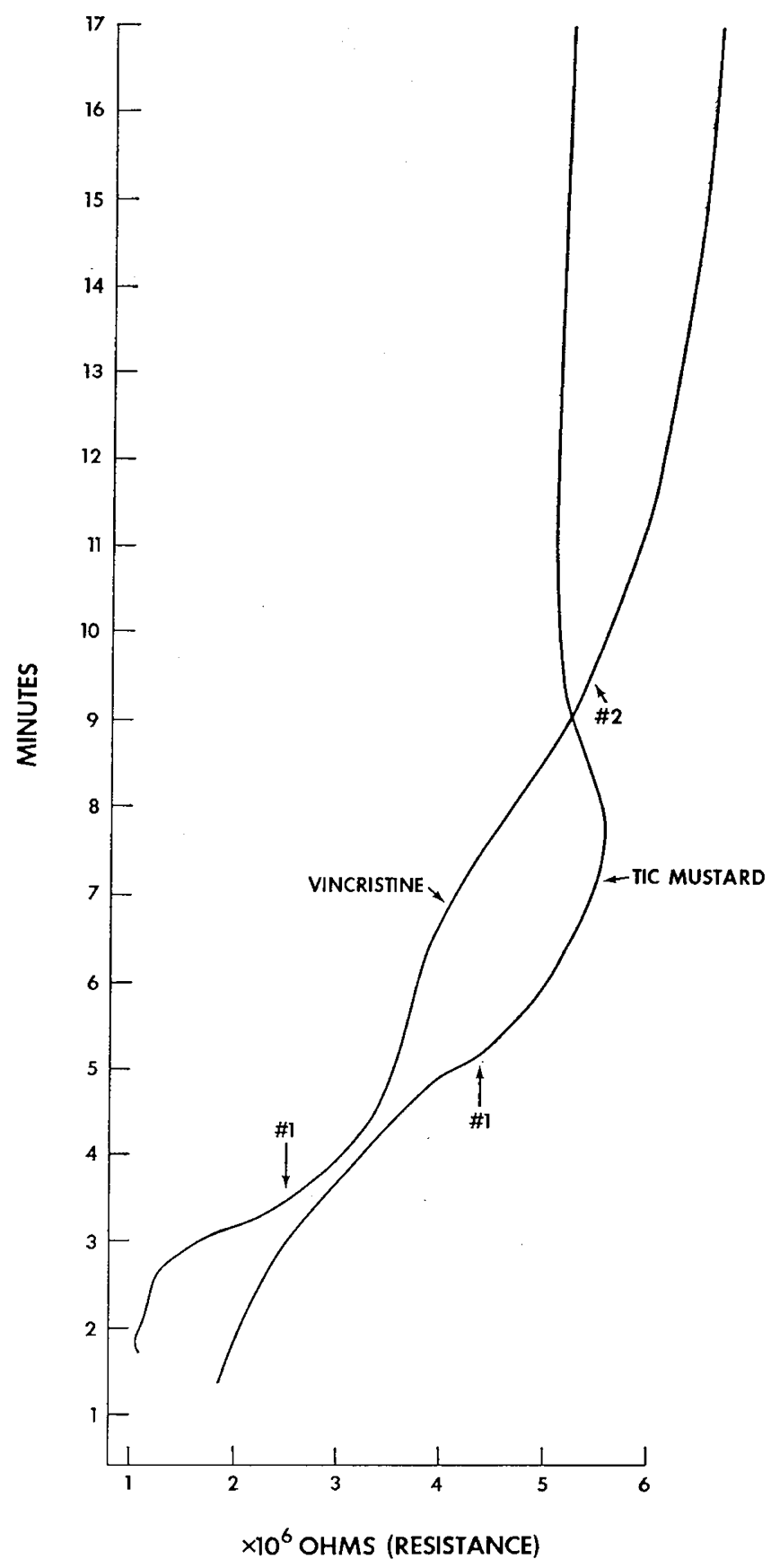

Fig. 3. Electrical resistance curves for 5-[3,3-bis(2-chloroethyl)-1triazeno]imidazole-4-carboxamide (TIC mustard) and vincristine. A normal plasma curve is omitted since vincristine parallels it.

\section{Electron Microscopy}

Three types of abnormalities of fibrin formation were seen by transmission electron microscopy. The pattern for each drug is summarized in Table VII. Sparse fibrin formation, frayed rope appearance of the 
strands, and loss of cross-striations were prominent in class $I-B, I I$, and $I I I$ agents.

\section{Discussion}

It is apparent from these data that high concentrations of some chemotherapeutic agents impede stable fibrin formation in vitro. Differences in functional and mor-

Table $V$. Electrical resistance changes for plasma containing chemotherapeutic agents

\begin{tabular}{lcc}
\hline \multirow{2}{*}{ Drug } & \multicolumn{2}{c}{ Second inflection, min } \\
\cline { 2 - 3 } & Unincubated & Incubated \\
\hline Class I-A & & \\
Vincristine & 8.7 & 9.2 \\
Vinblastine & 10.6 & 9.4 \\
Actinomycine D & 7.4 & 7.4 \\
Cytosine arabinoside & 8.8 & 9.0 \\
Class I-B & 23 & 15 \\
Daunorubricin & 11.8 & 11.8 \\
Adriamycin & 4.9 & 5.1 \\
L-Asparaginase & 21 & 33 \\
Class II & 8.2 & 8.3 \\
Methotrexate & $\infty$ & \\
Cyclophosphamide & & \\
Nitrogen mustard & 13.0 & $\infty$ \\
Class III & $\infty$ & \\
5-Fluorouracil & & \\
TIC mustard & & \\
Normal range & $8.7 \pm 2.2$ \\
Mean \pm 2 sD &
\end{tabular}

phologic studies of the third stage of coagulation suggest that several mechanisms are operative.

Agents grouped together as class $I-B$ do not alter the rate at which fibrin is formed although abnormal fibrin was visible by electron microscopy. Abnormal solubility in $5 \mathrm{M}$ urea uncorrected by an antifibrinolytic agent and delayed inscription of the second inflection of the electric resistance curve were observed. These data suggest inactivation of FSF. The electron micrographs resemble those seen when fibrin formed in the absence of FSF is washed in urea [15]. Resistance of urea

Table VII. Summary of electron microscopic pattern of fibrin ${ }^{1}$

\begin{tabular}{lccc}
\hline \multicolumn{1}{c}{ Drug } & Thickness & Frayed rope & $\begin{array}{c}\text { Cross- } \\
\text { striations }\end{array}$ \\
\hline Class I-A & & & \\
Vincristine & - & - & - \\
Vinblastine & - & - & - \\
Actinomycin D & - & - & - \\
$\quad$ Cytosine arabinoside & - & - & - \\
Class I-B & & & \\
Daunorubricin & + & + & + \\
Adriamycin & + & + & \pm \\
L-Asparaginase & + & + & - \\
Class II & + & + & + \\
Methotrexate & + & + & + \\
Cyclophosphamide & + & + & + \\
Nitrogen mustard & & & \\
Class III & + & + & + \\
5-Fluorouracil & + & + & + \\
TIC mustard & & + & + \\
\hline
\end{tabular}

$1-$ : normal; + : abnormal; \pm : slightly abnormal.

25 -[3,3-Bis(2-chloroethyl)-l-triazeno]imidazole-4-carboxamide

15-[3,3-Bis(2-chloroethyl)-1-triazeno]imidazole-4-carboxamide.

Table VI. Summary of studies of fibrin formation and stabilization in presence of chemotherapeutic agents ${ }^{1}$

\begin{tabular}{|c|c|c|c|c|c|c|c|c|}
\hline \multirow[b]{2}{*}{ Drug } & \multirow[b]{2}{*}{ Electron microscopy } & \multicolumn{3}{|c|}{ Serial thrombin time } & \multicolumn{2}{|c|}{ Electrical resistance } & \multicolumn{2}{|c|}{ Urea solubility } \\
\hline & & $\begin{array}{l}\text { Unincu- } \\
\text { bated }\end{array}$ & Incubated & $\underset{\text { with } \in-A C A^{2}}{\text { Incubated }}$ & $\begin{array}{c}\text { Unincu- } \\
\text { bated }\end{array}$ & Incubated & $\underset{\epsilon-\mathrm{ACA}}{\text { Without }}$ & $\underset{\epsilon-\mathrm{ACA}}{\text { With }}$ \\
\hline \multicolumn{9}{|l|}{ Class $I-A$} \\
\hline Vincristine & - & - & - & - & - & - & - & - \\
\hline Vinblastine & - & - & - & - & - & - & - & - \\
\hline Actinomycin $\mathrm{D}$ & - & - & \pm & \pm & - & - & - & - \\
\hline Cytosine arabinoside & \pm & - & $=$ & - & - & - & - & - \\
\hline \multicolumn{9}{|l|}{ Class $I-B$} \\
\hline Daunorubricin & + & - & - & - & + & + & + & + \\
\hline Adriamycin & + & - & - & - & + & + & + & + \\
\hline L-Asparaginase & + & - & - & - & - & - & + & + \\
\hline \multicolumn{9}{|l|}{ Class II } \\
\hline Methotrexate & + & \pm & + & - & + & + & + & - \\
\hline Cyclophosphamide & + & \pm & + & - & - & - & + & - \\
\hline Nitrogen mustard & + & - & + & - & + & + & + & - \\
\hline \multicolumn{9}{|l|}{ Class III } \\
\hline 5-Fluorouracil & + & + & + & + & + & + & + & + \\
\hline TIC mustard ${ }^{3}$ & + & + & + & + & + & + & + & + \\
\hline
\end{tabular}

1 - : normal; \pm : slightly abnormal; + : abnormal.

2 G-ACA : $\epsilon$-aminocaproic acid.

3 5- 3,3-Bis (2-chloroethyl)-1-triazeno]imidazole-4-carboxamide. 
solubility was restored for plasma containing L-asparaginase when the $\mathrm{pH}$ was adjusted to 7.6. Loewy [13] has observed less activity of FSF at extremes of $\mathrm{pH}$ and optimal activity at 7.6. Adjustment of $\mathrm{pH}$ of plasma containing daunomycin and adriamycin to $7.6 \mathrm{did}$ not prevent urea solubility, which suggests that, for these agents, the drug rather than the $\mathrm{pH}$ was responsible for loss of FSF activity.

The abnormalities seen with class II drugs are consistent with increased fibrinolysis. Incubation with $\epsilon$ ACA corrected thrombin time prolongation and urea solubility. Since FSF can serve as a substrate for fibrinolysins [11], it is not surprising to find a deficit of FSF activity.

Class III agents, exemplified by 5 -fluorouracil and TIC mustard, produced profound defects in all test systems. Although each represents an extreme of $\mathrm{pH}$ (8.0 and 3.7, respectively), neutralization of the plasma containing 5 -fluorouracil to 7.4 only partially corrected the thrombin time abnormality. Similar studies were not possible for TIC mustard, because it is insoluble at more alkaline $\mathrm{pH}$ [2]. The properties of its solvent and its failure to remain soluble under less acid conditions prevent us from distinguishing from solvent and solute as cause for defective fibrin formation.

The relevance of these findings to clinical situations remains to be proven. Studies of blood from patients who receive these agents are necessary to determine whether fibrin formation is impeded in vivo.

\section{Summary}

When a variety of chemotherapeutic agents reconstituted as for intravenous administration were mixed with normal plasma, defective fibrin was formed. Mechanisms varied and included increased fibrinolysis and inactivation of fibrin-stabilizing factor. In one instance the abnormality was related to the $\mathrm{pH}$ of the reconstituted drug rather than specific action of the agent.

\section{References and Notes}

1. Baggett, R. T., Hampton, J. W., and BrRd, R. M.: Fibrinolytic bleeding complicated by factor XIII defect. Arch. Intern. Med., 121: 539 (1968).

2. Carter, S. K., AND Newman, J. W.: 5(or 4)-[3,3-Bis(2-chloroethyl)-1-triazeno]-imidazole-4(or 5)-carboxamide (NSC-82196), Clinical brochure. Can. Chem. Rep. Suppl., 1: 63 (1968).

3. Chandler, A. B.: In vitro thrombotic coagulation of the blood: Method for producing a thrombus. Lab. Invest., 7: 110 (1958).

4. Cliffton, E. E., and Agostino, D.: The effect of nitrogen mustard on circulating cancer cells and pulmonary metastases

Copyright @ 1974 International Pediatric Research Foundation, Inc. from an experimental carcinoma. Surg. Gynecol. Obstet., 113: 160 (1961).

5. Cliffton, E. E., AND Agostino, D.: Effects of inhibitors of fibrinolytic enzymes on development of pulmonary metastases. J. Nat. Can. Inst., 33: 753 (1964).

6. Cliffton, E. E., And Grossi, C. E.: Effect of human plasmin on the toxic effects and growth of blood-borne metastasis of the Browne-Pearce carcinoma and the V2 carcinoma of rabbit. Cancer, 9: 1147 (1956).

7. FISHER, B., AND FISHER, E. R.: Experimental studies of factors which influence hepatic metastases. VIII. Effect of anticoagulants. Surgery, 50: 250 (1961).

8. Gasic, G. J., Gasic, T. B., ANd Stewart, C. C.: Antimetastatic effects associated with platelet reduction. Proc. Nat. Acad. Sci., 61: 46 (1968).

9. Jones, D. S., Wallace, A. C., and Frase, E. E.: Sequence of events in experimental metastasis of Walker 256 tumor: Light, immunofluorescent and electron microscopic observations. J. Nat. Can. Inst., 46: 493 (1971).

10. Kinsey, R. L., Price, E. B., AND Smrth, R. R.: Effectiveness of chemotherapy in relation to extravascular invasion by embolic tumor cells. Cancer, 13: 733 (1960).

11. Kolenich, J. J., Mansour, E. G., and Flynn, A.: Hematologic effects of aspirin. Lancet, 2: 714 (1972).

12. Laki, K., and YanceY, S. T.: Fibrinogen and the Tumor Problem. In: Fibrinogen, p. 359 (Marcel Dekker, New York, 1968).

13. Loewy, A. G.: Enzymatic control of insoluble-fibrin formation. In: Fibrinogen, p. 185 (Marcel Dekker, New York, 1968).

14. Lawrence, E. A., Bowman, D. E., Moore, D. B., and BernSTEIN, G. I.: A thromboplastic property of neoplasms. In: Surgical Forum, p. 694 (W. B. Saunders Company, Philadelphia, 1952).

15. SZALONTAI, S.: Submicroscopic morphology of the fibrinogenfibrin transition. In: Fibrinogen, p. 131 (Marcel Dekker, New York, 1968).

16. Wood, S., JR.: Pathogenesis of metastasis formation observed in vivo in the rabbit ear chamber. Arch. Pathol., 66: 550 (1958).

17. Eli Lilly and Company, Indianapolis, Ind.

18. Upjohn Company, Kalamazoo, Mich.

19. Merck Sharp and Dohme, West Point, Penna.

20. Lederle Laboratories, Pearl River, N. Y.

21. Mead Johnson Laboratories, Evansville, Ind.

22. Societa Farmaceutica Italia, Milan, Italy.

23. Roche Laboratories, Nutley, N. J.

24. Cancer Therapy Evaluation Branch of National Cancer Institute, National Institutes of Health, Bethesda, Md.

25. Parke-Davis and Company, Detroit, Mich.

26. Baltimore Biological Laboratories, Baltimore, Md.

27. Photovolt Company, New York, N. Y.

28. Model 600A, Keithley Instruments, Inc., Cleveland, Ohio.

29. Polysciences, Warrington, Penna.

30. Chase Instruments Corporation, Lindenhurst, N. Y.

31. This work was supported in part by United States Public Health Service Grant no. CA-08223 from the National Cancer Institute and Grant no. 5-505-RR07094-07.

32. Requests for reprints should be addressed to: Diane M. Komp, M.D., Department of Pediatrics, University of Virginia School of Medicine, Charlottesville, Va. 22901 (USA).

33. Accepted for publication September 26, 1973. 